\title{
Mobile Collaborative Informal Learning Design: Study of Collaborative Effectiveness Using Activity Theory
}

\author{
http://dx.doi.org/10.3991/ijim.v6i3.2090 \\ Hasnain Zafar Baloch, Aziziah Abdulrhaman, Noorminshah A Ihad \\ University of Technology Malaysia, Malaysia
}

\begin{abstract}
Smart Mobile Devices (SMD) are there for many years but using them as learning tools started to emerge as new research area. The trend to merge collaborative learning methodology by using mobile devices in informal context is important for implementation of Learner Centric Learning (LCL). Survey and numerous studies show that more than $95 \%$ of students in colleges are users of these smart mobile devices in developed world. Developing counties are also catching up and we can see this percentage is almost same in university level in these countries. Students are using SMDs for learning in some form. Higher education Institutions also try to embark their E-learning to Mobile learning (ML). The aim of this paper is to do propose operational framework for designing Mobile Collaborative Informal learning activities using SMDs. Show results of experimental and case study done to study the Mobile Collaborative Informal learning using Activity Theory (AT). Core Components of framework are Mobile Learning Activities/Objects, Wireless/Mobile Smart devices, Collaborative knowledge and Collaborative learning. The research mention here is its infancy stage.
\end{abstract}

Index Terms-Mobile Learning Design, Mobile Collaborative learning Objects, Collaborative learning, Informal learning.

\section{INTRODUCTION}

The Collaborative learning is the most researched method of learning of 21 century. With the popularity of social media and their availability to Smart devices make collaborative learning more interesting. Collaborative learning is when learner shares the learning activities with the team members and with the share of information learning takes place. Mobile Collaborative learning (MCL) is when learner is using Mobile and Wireless Smart Devices (MWSD) or simple say Smart devices (SD). MCL is extended form of Computer supported Collaborative learning where learner try to use SD to collaborate mostly in informal learning outside of normal class room or teacher supervision. Currently MCL can be seen in the form of formal learning in face-to-face Collaboration. Attention need to pay for the time learners spend on these smart devices and outside the classroom.

Laurillard's definition of mobile learning incorporates the critical pedagogical design input of the teacher: "Mlearning, being the digital support of adaptive, investigative, communicative, collaborative, "cooperative", and productive learning activities in remote locations, proposes a wide variety of environments in which the teacher can operate.” The research paper provides review within the field of Mobile Computing and Collaborative Learning using Activity theory and smart devices (SD).

The E-Learning guide defines mobile learning as "any activity that allows individuals to be more productive when consuming, interacting with or creating information mediated through a compact digital portable device that the individual carries on a regular basis, has reliable connectivity and fits in a pocket or purse” [1].

M-Learning actually complements E-learning. Putting the power of knowledge literally in the hands of today's society, in particularly students by enabling them to have 24/7 access to acquire and ascertain study materials via a mobile device, takes away the constraints of always having to be in a "classroom environment" for learning to be effective. According to Social constructive learning methodology the learner should involve and socially connected with the contents, members and learning activities.

\section{A. Mobile Learner}

In mobile-learning, the two primary concepts are mobile people and learners. Smart learners are supported by their will of mobile-learning and objects. While learning used to be measured in hours or days, these smaller chunks of learning are now being measured in minutes [2]. This is largely due to the massive amounts of information that we are now consuming or learning just-in-time to complete our daily tasks and the approaches or techniques used by the Mobile learner today.

\section{B. Mobile Collaborative Learning Object}

There are many successful approaches in E-learning and one of them is introduction of Learning Objects (LO) $[3,4]$. LO as an entity that should be self, interoperable, reusable, and describable, characteristics. Evolution of Learning Objects theory leads to Mobile Learning Object (MLO) $[5,6]$. The inclusion of the mobile part came from the approaches of m-learning, where the primary idea is to provide learning situations using as a means of communication and control mobile devices. The convergence between these two paradigms has resulted in mobile learning objects. According to Quinn [3] the MLO are described as independent entities and customizable allowing extended learning activities through mobile technology in an educational certain context. There are some studies where MLO does the Coordination and Collaboration among the learning activity as mentioned [7]. A new and emergent area within CSCL is that of mobile computer supported collaborative learning, MCSCL, [6] With the availability of 
$\mathrm{SD}$, learners are collaborating more and learning new forms of collaboration, which are used to deliver them through collaborative learning which some authors like Zurita [6] call it Mobile CSCL, that adds to the MbCLO model five factors for effective collaborative learning: individual liability, mutual support, positive interdependence, social interaction face to face and forming small groups. By combining all the features, we call learning object as Mobile collaborative learning object which include collaboration as a key element of LO.

\section{Wireless Mobile Smart Device (SD)}

Medium refers to mobile carriers and communication technology. Chang, Sheu, \& Chan [8] argue that the medium is a necessary element for carrying out the mobilelearning.

Examples of Mobile Learning Medium (MLM) are but not limited to these, laptops, tablets, PDAs (personal digital assistants), mobile phones, digital cameras, MP3 players, iPods, iPhones, iPad small electronic book readers and various multiple-function devices. Smart-phone, wireless Internet, access point, base stations, GPRS, General Packet Radio Services and other related technologies. The adoption of SD is tremendously high, with [9] stated that is projected that every learner will have a portable wireless device as recent data on mobile phone ownership in developed and developing countries reflects this [10]. The term SD will be used as Smart Devices (SD) as most of new smart devices are by default equipped with mobile and wireless features.

Convergence of E-learning, Mobile collaborative learning Objects, wireless and mobile smart devices and mobile learner creates more opportunities for Socialization and effective collaboration in Mobile learning. After going through research papers we found that Collaborative learning can be categorize as Formal , Informal , small scale group members not more than five and Large scale where group members are more than five and in certain cases whole class is collaboratively participating in LO as shown in the table 1 below.

TABLE I.

COLLABORATIVE LEARNING CATEGORIES

\begin{tabular}{|l|l|}
\hline $\begin{array}{c}\text { Formal Collaborative learn- } \\
\text { ing }\end{array}$ & $\begin{array}{c}\text { Informal Collaborative learn- } \\
\text { ing }\end{array}$ \\
\hline Mobile & Static \\
\hline Small Scale & large Scale \\
\hline Micro-collaboration & Macro-Collaboration \\
\hline Asynchronous & Synchronous (LIVE) \\
\hline
\end{tabular}

\section{BACKGROUND AND LITERATURE REVIEW}

\section{A. Mobile wireless Devices}

In 1945 we had the ancestor of current Mobile /Wireless smart devices in the form of Memex Device by Vannevar Bush. He explains his concept as follows: "A meme is a device in which an individual stores all his books, records, and communications, and which is mechanized so that it may be consulted with exceeding speed and flexibility.” [11]. Alan Kay and Adele Goldberg introduced the Dynabook concept at Xerox PARC thirty years later. Mark Weiser father of ubiquitous computing the idea was "to conceive a new way of thinking about computers, one that takes into account the human world and allows the computers themselves to vanish into the background "[12].

The most interesting theme across all these historical inventions of the future is that computers and smart mobile devices can be used to improve human intellect, collaboration and communication World War II slowed the introduction of television, but military training efforts had proven the importance for using audio-visual media in teaching [13]. The apparent success of audio-visual created a renewed interest in using it in the schools and in the decade following the war there were intensive research programs [13]. Early studies by educators tended to show that student achievement from classroom television was as successful as from traditional face-to-face instruction. A research study by Parsons showed slightly any differences in achievement, and Lapore and Wilson offered research showing that learning by television compared favourably with conventional instruction[13].

\section{B. Collaborative Learning}

History of collaborative learning as a teaching methodology can be traced back to ancient civilization. Collaborative learning was given a new lease of life in the second half of the 20th century when research showed that students learned faster and retained more when they became partners in the process of teaching and learning instead of remaining mere receivers of knowledge from their educators.

Almost all Prophets and religious preachers used social interaction rather than just reading through religious scriptures. Prophet Mohammad trained groups his companions in well socially connected environment. Learning has no school hours, learning and life goes together. Each aspect of student daily life activities (Walking, Sitting, going to ablution, praying, eating, his clothing, dealing with problems etc) is part of his learning. The student (Companion) live to learn and learn how to live from Prophets.

In traditional societies, small groups with high social knot make it possible to have wise man like Prophet Mohammad, Jesus, Buddha, and Nanak. Prominent examples of these personalities where learning took place with social interaction can be found in Malaysian/Indonesian societies in the form of idea of "Gotong royong” (the spirit of mutual help in a society or community).

The collaboration context is changed and replaced by technology where we try to communicate and collaborate using mobile phones, internet and other mobile/wireless smart devices.

Collaborative learning is a situation in which two or more people learn or attempt to learn something together. Collaborative learning is heavily rooted in Vygotsky's views that there exists an inherent social nature of learning which is shown through his theory of zone of proximal development. Collaborative learning is mostly link to Cooperative learning difference is lack of shared knowledge. MCL is seen as a future model which support lifelong learning enable learner to learn anytime, anywhere, on any device at his own pace. 


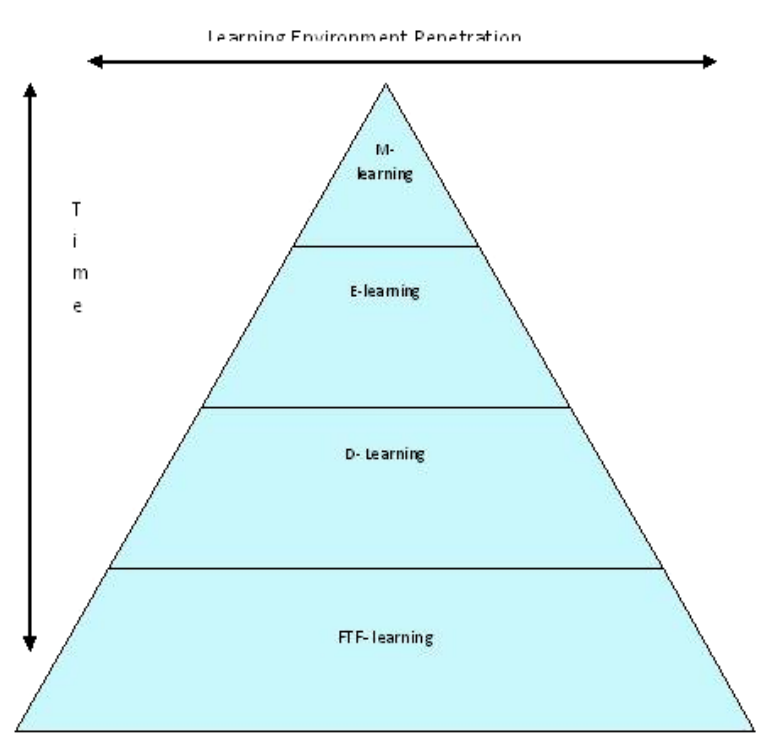

Figure 1. A Hierarchy of Learning Methodologies. Source: Investigator

Many features in the phone and other wireless mobile smart devices have potential to support Mobile collaborative learning. According to[14] mobile device used in mobile learning could be exploited with the features i.e portability, Social connectivity, context sensitivity, connectivity, and individuality.

Over the last ten years, mobile learning has emerged as killer application and significant projects around the world started [5].Earlier research focus on mobility of technology where learner acquire knowledge and skill thought use of mobile technology, anywhere, anytime [15] Now a day's mobile learning is defined as the mobility of learner across locations and context, taking advantages of the learning opportunities offered by the latest technologies in the environment. Pachler and colleagues [16] claim for the mobile complex, a triad of agency, structures, and cultural practices, as mechanisms for understanding how to develop educational practices to meet the new literacy of technology use. This will allow learner and instructor to engage in analysis and design of MCL object which suits the learner Context, this scenario need innovative method for data capture and data analysis.BBC bitsize Mobile is service which let students to use mobile phones to revise their study material while they are away from school. Revise on the go provides quizzes and lecture material in MP3 format.

In figure 1 the penetration of different learning methodologies shown and most of these methods are base on FTF learning Model. Learning will be next killer application for Web as said by John Chambers, CEO Cisco System. With advancement of wed to mobile devices M-learning is picking up.

Mobile Collaborative Learning is interaction of Mobile wireless networking, Mobile learning and SD. As learner are more mobile now and most of the formal and informal learning took place by learner using some kind of mobility (Mobile device, Mobile data).

\section{RESEARCH PROBLEM:}

Major challenge for researcher will be how to tap the oppertunities to integrate Smart Mobile Wireless Devices
TABLE II.

DIFFERENT PROJECTS IN THE AREA OF COLLABORATIVE LEARNING.

\begin{tabular}{|c|c|c|c|c|}
\hline $\begin{array}{l}\mathbf{N} \\
\mathbf{0}\end{array}$ & Title /year & Author & $\begin{array}{l}\text { Cate- } \\
\text { gory }\end{array}$ & Activity \\
\hline 1 & $\begin{array}{l}\text { Classtalk: a class- } \\
\text { room communica- } \\
\text { tion system } \\
\text { for active learning }\end{array}$ & Dufresne & Formal & $\begin{array}{l}\text { Collabora- } \\
\text { tion small } \\
\text { group }\end{array}$ \\
\hline 2 & MOOsburg 2002 & $\begin{array}{l}\text { Umer } \\
\text { Farooq el. } \\
\text { d }\end{array}$ & Informal & $\begin{array}{l}\text { Network } \\
\text { Commu- } \\
\text { nity }\end{array}$ \\
\hline 3 & $\begin{array}{l}\text { "Networked PDAs in } \\
\text { a Community of } \\
\text { Learners", } \\
\text { Proceedings of } \\
\text { CSCL 2002, pp. } \\
\text { 548-549. }\end{array}$ & $\begin{array}{l}\text { Lundby, } \\
\text { K., } \\
\text { Smørdal, } \\
\text { O., Lar- } \\
\text { sen, A., } \\
\text { Fjuk, A., }\end{array}$ & $\begin{array}{l}\text { Informal } \\
\text {, feild } \\
\text { study , } \\
\text { Medical } \\
\text { student }\end{array}$ & $\begin{array}{l}\text { More } \\
\text { Inforam- } \\
\text { tion des- } \\
\text { simination }\end{array}$ \\
\hline 4 & $\begin{array}{l}\text { WILD: How Wire- } \\
\text { less Handhelds May } \\
\text { Change CSCL”, } \\
\text { Proceedings of } \\
\text { CSCL 2002, pp. 51- } \\
60 .\end{array}$ & $\begin{array}{l}\text { Ro- } \\
\text { schelle, J. } \\
\text { and Pea, } \\
\text { R., }\end{array}$ & $\begin{array}{l}\text { Formal, } \\
\text { In class }\end{array}$ & Maths \\
\hline 5 & $\begin{array}{l}\text { "Toolkit for Emerg- } \\
\text { ing learning land- } \\
\text { scapes supported by } \\
\text { Ubiquitious Comput- } \\
\text { ing” } 2010\end{array}$ & Skipol & $\begin{array}{l}\text { Informal } \\
\text {, case } \\
\text { study }\end{array}$ & $\begin{array}{l}\text { Museum } \\
\text { collabora- } \\
\text { tive } \\
\text { study,Used } \\
\text { of } \\
\text { D*TELLl }\end{array}$ \\
\hline 6 & $\begin{array}{l}\text { "A conceptual } \\
\text { framework based on } \\
\text { Activity theory for } \\
\text { Mobile CSCL “ }\end{array}$ & Zurita & $\begin{array}{l}\text { Formal } \\
\text { /Informal }\end{array}$ & $\begin{array}{l}\text { Maths } \\
\text { MCSCL } \\
\text { Objects }\end{array}$ \\
\hline 7 & $\begin{array}{l}\text { "Face-to-Face Col- } \\
\text { laborative Learning } \\
\text { Supported by Mobile } \\
\text { Phones”2011 }\end{array}$ & $\begin{array}{l}\text { Nuss- } \\
\text { baum }\end{array}$ & $\begin{array}{l}\text { Informal } \\
\text { /Fomal } \\
\text { Small } \\
\text { Group }\end{array}$ & MCQ \\
\hline 8 & $\begin{array}{l}\text { Mobile learning } \\
\text { Society }\end{array}$ & Sharples & & \\
\hline 9 & $\begin{array}{l}\text { "Supporting Mobile } \\
\text { Collaborative Activi- } \\
\text { ties through Scaf- } \\
\text { folded Flexible } \\
\text { Grouping "2011 }\end{array}$ & $\begin{array}{l}\text { Ivica } \\
\text { Boticki, } \\
\text { Chee-Kit } \\
\text { Looi and } \\
\text { Lung- } \\
\text { Hsiang } \\
\text { Wong }\end{array}$ & & \\
\hline 10 & $\begin{array}{l}\text { SMILE: Stanford } \\
\text { Mobile Inquiry- } \\
\text { based Learning } \\
\text { Environment }\end{array}$ & $\begin{array}{l}\text { Sunmi } \\
\text { Seo,Aaro } \\
\text { n Sharp, } \\
\text { and Paul } \\
\text { Kim }\end{array}$ & $\begin{array}{l}\text { Formal } \\
\text { /Group }\end{array}$ & Quiz \\
\hline
\end{tabular}

into Educational Padegogy and make sure to design Mobile Collaborative activities. This new learning landscape should be highly situated,personal, Collaborative, and group/learner centeric. Most of the Mobile learner complains about lack of Collaboration when they work in small groups on any task which can be considered as Project based learning. In Some cases the collaboration/Cooperation is less than communication which leads to non effective collaboration Most of the students are equipped with SD, with the availability of Wireless network access and combination of SD there are many oppor- 
tunities for the learner to use these SD effectively. Most of the hi-tech technologies are not explore fully to fulfil the needs of students. The research will investigate the perception of learner on effectiveness of using Wireless Mobile smart devices for enhancing Collaboration in Mobile learning. My research will study how Mobile Wireless Smart devices that already used by the learner can be utilized effectively. Main aim of research is "To investigate the impact of Wireless Mobile Smart Devices on Mobile Collaborative learning." To elaborate more following are the research sub-questions

SQ1: What is the perception of learner about using smart devices in Mobile Collaborative Informal learning?

Objective: To conduct exploratory research to find out more about learner in Mobile Collaborative Informal learning. Once we know what exactly the learner's perception. This will help to design better Framework for MCILO.

H1: Mobile Smart devices have positive effect on MCIL.

SQ2: How do the SD, Mobile learning Objects, and educational Activities influence Collaboration in Mobile learning?

Objective: To check what is the effective of SD on learner when it comes to group of learner working on Science project what type of activities help them to collaborate and finish the task in hand.

H2: MCILO should let the team member collaborate live or instant as much near to as face-to face or virtual face-to-face.

SQ3: Does SD help higher Institution students to collaborate effectively?

Objective: What extent can these SDs are utilized to support learner interactivity, collaboration, communication, reflection and interest, and thus provide pedagogically rich learning environments that engage and motivate the learner? To what extent can WMDs be used to harness the potential of current and emerging social constructivist e-learning tools?

H3: It depends on the MCLIO engagement. If MCLIO can let team member engage until they reach agreement.

Mobile Collaborative learning is new but as personal mobile and wireless technologies for learning become more and more widespread and cheap, studies are starting to show evidence for the value of incorporating mobile wireless devices in teaching and learning[17].Also substantial issued, including conflicts between informal learning with personal mobile devices and traditional classroom education [5]. Learners are adopting new skills and literacy's enabled by Wireless Mobile Smart Device, such as SMS texting, MMS, mobloging, mobile twittering, QR Codes, and mobile video creation. New generation of SD will offer further enhanced possibilities, of education services, more collaboration , more learning activities and educational media will matched to learner's contact and interests.

The research question investigates beyond "which" smart device is used by the learner rather we focus on cause- and - effect relationship and how learner uses these SD effectively. This research will study how Mobile wireless smart devices that already used by the learner can be implemented to increase effective collaboration which leads to knowledge sharing and learning.

\section{ReseARCh Design AND Methodology:}

Researchers see Collaborative learning as a process of social conversation, where learner and instructors build knowledge by cooperating and sharing information interactively. This makes Mobile learning multichannel and multi-direction way to share and transmit the knowledge. The construction of knowledge will happen as the results of mutual understanding of learner's existing understanding to make meaningful collaboration to develop new knowledge. However, in groups each learner have own understanding of a problem domain, each of them will take different approach and have different opinion and strategies regarding a particular issue [18] there are chances of conflicts during collaboration. Piagetian theory [6] suggests that these social -cognitive conflicts may enhance the effectiveness of Collaborative learning. In order to reach to some solution by negotiation, researchers believe that social mediation is important [19]; [20], therefore it would be better to incorporate mobile computing into this situation and investigate real-world environment where learner become part collaborative learning group using Smart devices connect by wireless network to gain knowledge constructively. Arrigo and Chiappone example showed that mobile technology would support social constructivist learning.

Community of practice is term used in social constructivist approach to learning and mostly used in Management of Organizational knowledge. Community of practice is a group of people (learner) who share a concern sharing same problems, the group learn and increase their knowledge by collaborating and interacting regularly [21]. Wenger develop detailed Model for community of practice and argued strongly for its role in promoting learning. According to this model learner engage themselves in activities which bring knowledgeability of each learner and explore new learning context among the group members. These are the most related theories to Mobile learning, Collaborative learning and Mobile wireless smart devices.

\section{A. Research Model}

For the sack of theoretical understating of issues of Complexity and contingency afforded by Mobile learning, Collaborative learning, Mobile /wireless and ubiquitous technology. We will first survey the theories mentioned in above section and find out their limitations in explaining the impact of SD in supporting Mobile Collaborative learning. Try to find answers to these limitations.

The work for this research will focus research model shown in the Figure 2. Set of MCL objects and formal and informal scenarios will be developed to define and illustrate the Mobile Collaborative learning using SD (SQ2). Scenarios can be created after carefully knowing the perception and impact of SD on learner in UTM and How to incorporate SD to MCL objects (SQ2). Research model will seek to have learner in final year from different schools/department and MCL objects of different types, e.g Collaborative games, supervised and unsupervised project based learning.

Literature study comprise of empirical and qualitative research relating to impact of SMD on Mobile Collaborative learning will be listed in chapter two. The key word used in literature Mobile learning, Collaborative learning , Cooperative learning , In-group Learning ,Project based 


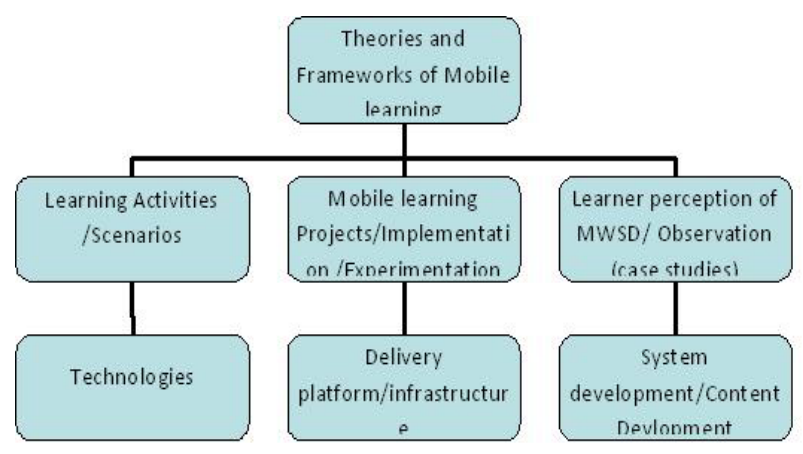

Figure 2. Explain how the research will proceed as research model to follow.

learning, real world learning, Computer-supported collaborative work, learning by doing, technology-enhanced learning (TEL), Learning Objects. Pretest and post test of learning can show the impact of MWSD impact on Mobile Collaborative learning.

To perform details design about the Mobile Collaborative Informal Learning Object/Activity (MCILO/A) we come up with Model influenced by the researchers from Collaborative and Mobile Learning. After doing the detail study figure 3 explain details of MCLO framework. Any learning activity which meets the elements in Figure 3 can lead us to effective collaboration and the team /group can achieve their goals. Once each team member share and collaborate more the level of share knowledge will be very high. As shown in figure 4.

\section{ReseARCh Methodology}

Researcher will do a literature study, an experimental pilot study at UTM and three experimental studies at other universities in Malaysia (which meet the M-learning readiness criteria). For data collection researcher will use the Quantitative method by using the questionnaire. However qualitative approach can only be applied to UTM where the researcher is based and research is focused at.

Multiple cases create more robust theories 'because the propositions are more deeply grounded in varied empirical evidence' [22]. Figure 5 shows the overall operational framework for the designing of MCILO/A.

\section{A. Experiments}

\section{1) Context}

All pilot projects will be carried out in UTM Schools/Departments,

- At intermediate level to advance level courses or students at their 3-4th year or Final year students by research.

\section{2) Task}

Members will receive same task as they were without SD. Each scenario will have scenario-specific instructions.

\section{3) Measures}

\section{Communication}

- Quantitative: No of messages, Frequency of messages, messages length, social networking analysis.

- Qualitative 1: messages content in terms of physical attributes such as text, sound (e.g., mp3, Wav, WMA), static images (e.g., Jpg, bmp, gif,), and dynamic images (e.g., mpg, mov, wmv)

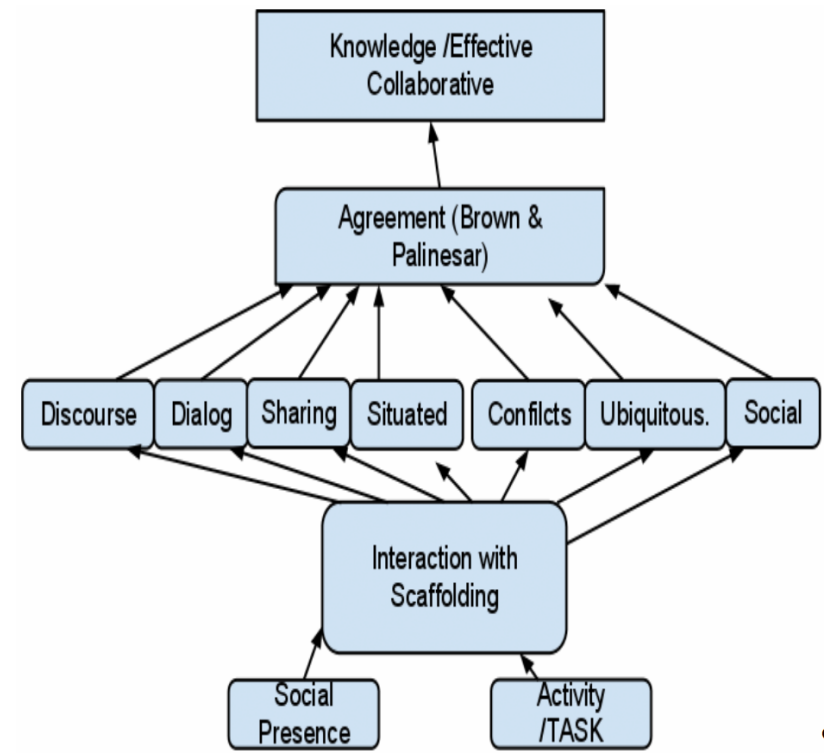

Figure 3. Effective Collaborative factors.

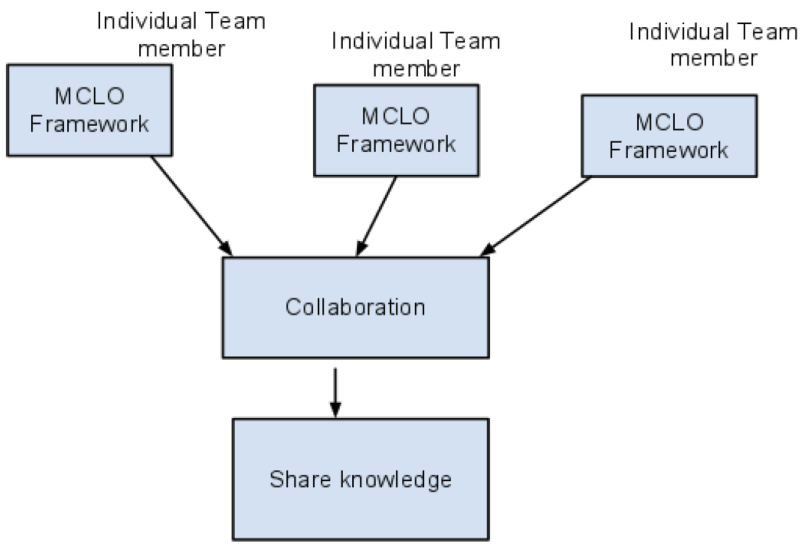

Figure 4. Collaboration key for Knowledge sharing.

Collaboration /Community formation

- Social presence: degree to which the other in a communication appears to be a 'real' physical person via Social Presence Scale [23].

- Sociability: degree of perceived sociability of an environment; that is the extent to which an environment can facilitate the emergence of a social space via Sociability Scale [24].

- Social Space: the degree of perceived quality of a social space existing in a distributed learning group via Social Space Scale [23].

\section{4) Satisfaction}

- Supervisor / Learner: Satisfaction with the MCL,MCLO and the interaction with the supervisor

(Questionnaire on Instructor Interaction and with fellow learners [25]).

\section{CONCLUSION AND FUTURE WORK:}

The work presented is at its preliminary stage and the model presented here will be enhanced and used in PhD research. Need to explore more about Malaysian and in particularly UTM context. This paper demonstrates how 
Mobile Collaborative learning principles of constructive, self-directed, collaborative and contextual learning apply to PBL. The available research results are reviewed and discussed. Design-based research is needed in which it is investigated how theoretical claims can be transformed into effective Collaborative learning should be investigated: research that enriches our understanding of the nature of Mobile Collaborative learning.

\section{REFERENCES}

[1] Wexler, S.B., J. Metcalf, D. Rogers, D. and Wagner, E, MOBILE LEARNING What it is, why it matters, and how to incorporate it into your learning strategy. 2008.

[2] Stawarski, C.A., \& Gadd, R. , Evaluating mLearning. ASTD Handbook for Measuring and Evaluating Training., 2010.

[3] Clark, Q., Designing mLearning: Tapping into the Mobile Revolution for Organizational Performance. Pfeiffer., 2011.

[4] Kukulska-Hulme, A.a.S., Lesley, An overview of mobile assisted language learning: From content delivery to supported collaboration and interaction. ReCALL, 2008. 20(3): p. 271-289. http://dx.doi.org/10.1017/S0958344008000335

[5] Sharples, M., Taylor, J., \& Vavoula, G. , A theory of learning for the mobile age. The Sage handbook of e-learning research, 2007: p. pp. 221-247.

[6] Zurita, G. and M. Nussbaum, Computer supported collaborative learning using wirelessly interconnected handheld computers. Computers \&amp; Education, 2004. 42(3): p. 289-314. http://dx.doi.org/10.1016/j.compedu.2003.08.005

[7] Ayala, G. and S. Castillo. Towards Computational Models for Mobile Learning Objects. in Wireless, Mobile, and Ubiquitous Technology in Education, 2008. WMUTE 2008. Fifth IEEE International Conference on. 2008.

[8] Chan, T., Roschelle, J., Hsi, S., Kinshuk, Sharples, M., Brown, T., Patton, C., Cherniavsky, J., Pea, R., Norris, C., Soloway, E., Balacheff, N., Scardamalia, M., Dillenbourg, P., Looi, C., Milrad, M., \& Hoppe, U. , One-to-one technology-enhanced learning: An opportunity for global research collaboration. Research and Practice in Technology Enhanced Learning, 2006. 1(1): p. 3-29. http://dx.doi.org/10.1142/S1793206806000032

[9] Bull, G., Bull, G., Garofalo, J., \& Harris, J., Grand Challenges : Preparing for the technological tipping point Technology and Teacher Education, 2002. 2(1).

[10] Gartner, Gartner Says Sales of Mobile Devices in Second Quarter of 2011 Grew 16.5 Percent Year-on-Year; Smartphone Sales Grew 74 Percent. 2011.

[11] Bush, V., As We May Think. theatlantic, July 1945(176): p. 101108.

[12] M, W., The Computer for the 21st Century. Scientific American 1991. 265(3): p. 66-75.

[13] Jeffries, M., Research in Distance Education. IPSE.

[14] Klopfer, E., Squire, K and Jenkins, H, Environmental Detectives: PDAs as a window into a virtual simulated world. Proceedings of
IEEE International Workshop on Wireless and Mobile Technologies in Education., 2002: p. 95-98. http://dx.doi.org/ 10.1109/WMTE.2002.1039227

[15] Geddes, S., Mobile learning in the 21st century: Benefit for learners. . Knowledge Tree e-journal., 2004.

[16] Pachler, N.B., Ben; Cook, John. , Mobile Learning. Structures, Agency, Practices. Springer, 2010.

[17] McFarlane, A., Triggs, P. \& Yee, W., Researching mobile learning. 2008.

[18] Dufresne, R.J., Gerace, W. J., Leonard, W. J., Mestre, J. P., \& Wenk, L. , Classtalk: a classroom communication system for active learning. Journal of Computing in Higher Education, 1996. 7(2): p. 3-47. http://dx.doi.org/10.1007/BF02948592

[19] Brown, J.S., Collins, A., \& Duguid, P. , Situated cognition and the culture of learning. Educational Researcher, 1989. 18: p. 32-42.

[20] Vygotsky, L., Mind in Society: the Development of Higher Psychological Processes.

[21] . Edited Cambridge Mass, 1978.

[22] Wenger, E.M., Richard; Snyder, William M., Cultivating Communities of Practice. Harvard Business Press, 2002. 1.

[23] GRAEBNER, K.M.E.M.E., THEORY BUILDING FROM CASES: OPPORTUNITIES AND CHALLENGES. Academy of Management Journal, 2007. 50(1): p. 25-32. http://dx.doi.org/10.5465/AMJ.2007.24160888

[24] Kreijns, K., Kirschner, P.A., \& Jochems, W, Supporting social interaction for group dynamics through social affordances in CSCL: Group awareness widgets. Biennial European Conference for Research on Learning and Instruction (EARLI), 2003.

[25] Kreijns, K., Kirschner, P. A., Jochems, W., \& Van Buuren, Measuring Perceived Sociability of Computer-Supported Collaborative Learning Environments. Computers \& Education, 2007. 49: p. 176-192. http://dx.doi.org/10.1016/j.compedu.2005.05.004

[26] Wubbels, T., \& Levy, J.. Do you know what you look like? The Falmer Press., 1993.

\section{AUTHORS}

Hasnain Zafar is with the University of Technology Malaysia as PhD candidate in Deaprtement of (e-mail: hsnainzafar@ieee.org).

Azizah Abdul Rahman is Associate Professor at Faculty of Computer Science and Information system, Department of Information system in University of Technology Malaysia. (e-mail: azizahar@utm.my ).

Noorminshah A Ihad is with the Faculty of Computer Science and Information system, Department of Information system in University of technology Malaysia as Senior Lecture. (e-mail: minshah@utm.my).

Received11 April 2012. Published as resubmitted by the authors 24 June 2012. 
SHORT PAPER

Mobile Collaborative Informal Learning Design: Study of Collaborative EFFeCtiveness Using Activity Theory

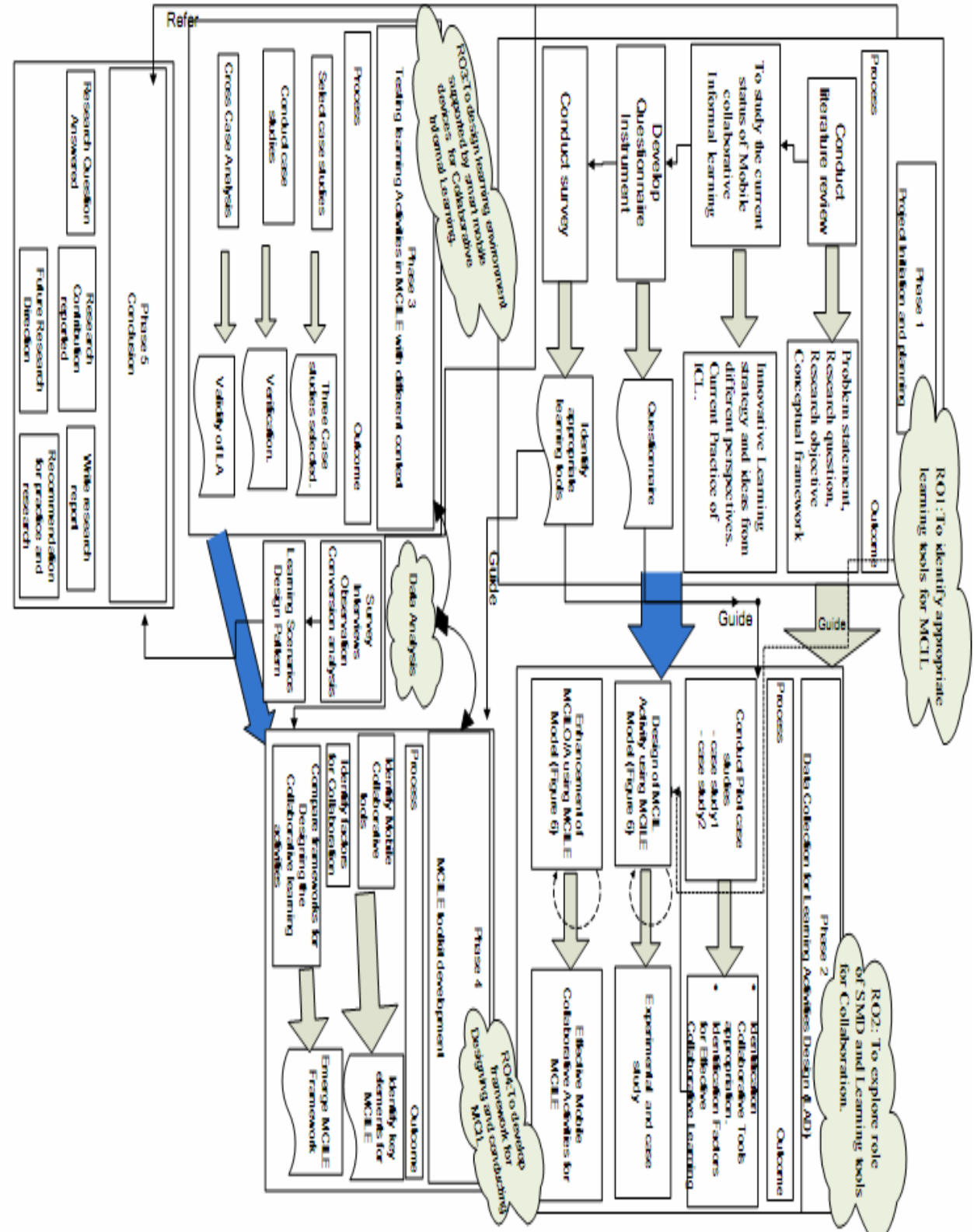

Figure5 : Opertioanl framework for Designing MCILO/A 
SHORT PAPER

Mobile Collaborative Informal Learning Design: Study of Collaborative EFFectiveness Using Activity TheORY

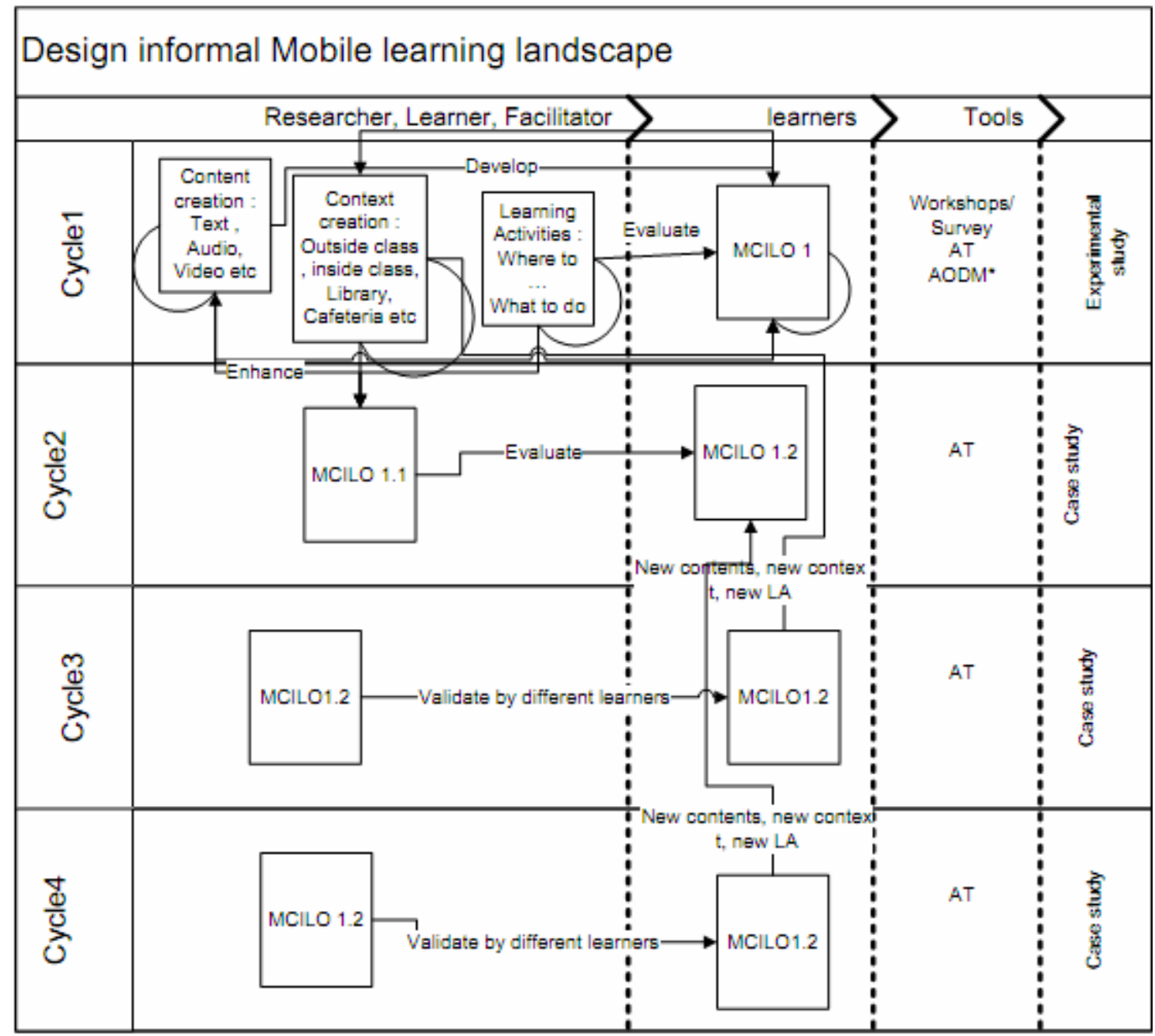

Figure 6: Desing iteriation for desinging learnnig activity 